Kyoto University,

Graduate School of Economics

Research Project Center Discussion Paper Series

Fisheries Subsidies and Management in Open Economies

Naoto Jinji

Discussion Paper No. E-11-004

Research Project Center

Graduate School of Economics

Kyoto University

Yoshida-Hommachi, Sakyo-ku

Kyoto City, 606-8501, Japan

October 2011 


\title{
Fisheries Subsidies and Management in Open Economies*
}

\author{
Naoto Jinji ${ }^{\dagger}$ \\ Kyoto University
}

This version: September 28, 2011

\begin{abstract}
The WTO members are conducting negotiations to clarify and improve disciplines on fisheries subsidies at the Doha Round. In this paper, I investigate how worldwide subsidy reform in the fisheries sector could affect fisheries output and resource stocks in a trading equilibrium. I demonstrate that the effects of a reduction in subsidies on fisheries output will differ, depending on the conditions of the economy and fisheries management in different countries. A possible outcome of a reduction in non-capacity-enhancing subsidies is that fisheries output will rise in countries where catch quotas are not enforced and remain the same in countries where catch quotas are strictly enforced, expanding the total supply of fisheries products in the short run. In the long run, the world fisheries resource stock may be reduced.
\end{abstract}

Keywords: fisheries; subsidies; WTO; SCM Agreement; variable labor supply.

JEL classification: F13; F18; Q22; Q27

*This paper is a revised version of the paper entitled "Subsidies, Fisheries Management, and International Trade" (RIETI Discussion Paper Series No. 10-E-023). I would like to thank Kenzo Abe, Masahisa Fujita, Tsuyoshi Kawase, Yoshizumi Tojo, Ryuhei Wakasugi, Nobuyuki Yagi, the members of the research project "Study on the WTO's SCM Agreement" at the Research Institute of Economy, Trade and Industry (RIETI), and two anonymous referees for helpful comments and suggestions on earlier versions of the paper. Financial support from the Japan Society for the Promotion of Science under the Grand-in-Aid for Scientific Research (C) (No. 21530221) is gratefully acknowledged. Any remaining errors are my own.

${ }^{\dagger}$ Faculty of Economics, Kyoto University, Yoshida-honmachi, Sakyo-ku, Kyoto 606-8501, Japan. Phone \& fax: +8175-753-3511. E-mail: jinji@econ.kyoto-u.ac.jp. 


\section{Introduction}

Enormous amounts of money have been spent worldwide on subsidies for the fisheries industries. Many of those subsidies are possibly detrimental to resource conservation and management (Clark et al., 2005). This is mainly because the subsidies support overcapacity in the fisheries.

While it is not easy to define and obtain accurate data on fisheries subsidies, some estimates are available. ${ }^{1}$ According to the Organisation for Economic Co-operation and Development (OECD 2006), government financial transfers (GFTs) to marine capture fisheries in OECD countries amounted to US $\$ 6.47$ billion in 2003. This represented about $20 \%$ of the value of world production (i.e., landings) in the industry. Most of the GFTs were devoted to management, research, and enforcement $(38.8 \%, \$ 2,508$ million) and infrastructure (35.0\%, $\$ 2,263$ million). Funds were also spent on decommissioning schemes (6.7\%, $\$ 432$ million), income support (6.7\%, \$435 million), investment and modernization $(3.2 \%, \$ 206$ million), access payments (3.0\%, $\$ 194$ million), and other cost-reducing transfers and direct payments (7.0\%, $\$ 454$ million). The last item includes price support schemes.

Based on case studies of Japan, the European Union, Norway, the United States, Russia, and China, Milazzo (1998) estimates the aggregate level of subsidies to fisheries in the world as US\$14.0-20.5 billion annually. ${ }^{2}$ He categorizes fisheries subsidies into (i) budgeted subsidies, (ii) unbudgeted subsidies, (iii) cross-sectoral subsidies, (iv) conservation subsidies, and (v) resource rent subsidies. ${ }^{3}$

Khan et al. (2006) and Sumaila et al. (2006) provide another estimate. Khan et al. (2006) estimate global non-fuel fisheries subsidies for 11 subsidy types from the database of subsidy programs reported in marine capture fisheries for 144 coastal countries (both developed and developing countries) from 1995 to 2005. They estimate that global non-fuel subsidies are US $\$ 25.7$ billion annually. About $49 \%$ (US $\$ 12.7$ billion) is provided by 38 developed countries and the remaining $51 \%$ (US $\$ 13.0$ billion) by 103 developing countries. In developed countries, subsidies for fisheries management programs and services are the major program (US $\$ 5.1$ billion). In developing countries, on the other hand, fishing port construction and renovation programs (US $\$ 7.3$ billion) and fishery development projects and support services (US $\$ 2.2$ billion) are the major programs.

The use of fisheries subsidies is discussed at the World Trade Organization (WTO). Members of the WTO are currently conducting negotiations to clarify and improve disciplines on fisheries subsidies in the Rules Negotiations at the Doha Round (WTO 2007, 2008, 2011). At present, there are no specific regulations on fisheries subsidies in the WTO. The new regulations on fisheries subsidies are planned

\footnotetext{
${ }^{1}$ For detailed discussion on how to define fisheries subsidies, see OECD (2006) and Khan et al. (2006).

${ }^{2}$ Data include different years in the 1990s.

${ }^{3}$ Budgeted subsidies include development grants, state investments, foreign access payments, market promotion, and price supports. Unbudgeted subsidies include subsidized loans, fuel tax exemptions, and income tax deferrals. Crosssectoral subsidies include aids to shipbuilding and aids to fisheries infrastructure. Conservation subsidies include vessel and fishing permit buybacks, stock enhancement, and R\&D in clean harvesting gear. Finally, resource rent subsidies include user fees.
} 
as additions to the Agreement on Subsidies and Countervailing Measures (SCM Agreement) as Annex VIII. In the negotiations, the prohibition on certain forms of fisheries subsidies that may contribute to overcapacity and overfishing was proposed. At the same time, the establishment of appropriate and effective special and differential $(\mathrm{S} \& \mathrm{D})$ treatment for developing and least-developed countries is also discussed in the new regulations. In the draft of the new regulations (WTO 2007), exceptions (both general and S\&D) are conditioned upon the establishment and operation of fisheries management systems and measures. It is, however, controversial whether the WTO, which is not a fisheries management organization, should use binding conditionality concerning fisheries management. ${ }^{4}$

The main purpose of this paper is to analyze how fisheries subsidies will affect the incentive of people in the fisheries sector. I consider two types of subsidies: one type is subsidies for income support; another type is subsidies for price supports that raise the domestic producer price of fisheries products. In the Draft Consolidated Chair Texts of the AD and SCM Agreements (WTO 2007), which is the basis for negotiations at the Doha Round, these two types of subsidies are included in subsidies that should be prohibited. ${ }^{5}$ Thus, an analysis of those subsidies could provide some implications for negotiations at the WTO. I illustrate how the effects of reducing existing subsidies on fisheries output will differ, depending on the conditions of the economy. I construct a simple model of two sectors: fisheries and manufacturing. A key element is variable labor supply. Each worker chooses the optimal supply of labor by taking into account the substitution between consumption of goods and leisure.

The main results are as follows. First, in a small open economy (SOE) where catch quotas are not enforced and there are no alternative employment opportunities for workers in the fisheries sector, a permanent reduction in subsidies for income support will increase fisheries output in the short run. This is because workers in the fisheries sector try to partially offset reductions in income from cuts in subsidies by increasing labor, which results in a longer time spent fishing. In the long run, the subsidy cut reduces the steady-state fish stock due to increased fishing. A reduction in subsidies for raising the domestic producer prices of fish has a similar effect if the elasticity of substitution between leisure and the aggregate consumption goods is low. Second, in an SOE where catch quotas are strictly enforced and there are alternative employment opportunities for workers in the fisheries sector, a permanent reduction in fisheries subsidies has no effect on total fisheries output or on the steady-state fish stock as long as catch quotas are binding. A further reduction in fisheries subsidies may cause catch quotas to be no longer binding. In such a case, a reduction in subsidies reduces fisheries output both in the short run and in the long run and may increase the steady-state level of fish stock. Third, in the trade between

\footnotetext{
${ }^{4}$ The present situation of the negotiation is "too little convergence on even the technical issues, and indeed virtually none on the core substantive issues" (WTO 2011, p. 1). There has been no progress in the negotiation since WTO (2011) was circulated in April 2011.

${ }^{5}$ In the Chair Texts, Annex VIII (pp. 87-93) of the SCM Agreement addresses fisheries subsidies. In Article I.1, "income support for natural or legal persons engaged in marine wild capture fishing" and "price support for products of marine capture fishing" are identified as (e) and (f) of subsidies that shall be prohibited (WTO 2007).
} 
two countries, the world relative price of fisheries product is endogenously determined and hence is affected by any change in fisheries subsidies. If the relative supply of fisheries product increases, then the world relative price will decrease. This indirect effect through price changes reinforces the direct effect of reducing fisheries subsidies. Consequently, even in the case of trade between two countries, subsidy reform that reduces either income supports or price supports can expand the world catch of fish in the short run. In the long run, the world fish stocks will be reduced by the subsidy reform unless the price change is large. The results in this paper suggest that proper management of fisheries resources is important for subsidy reform to mitigate overfishing and conserve fisheries resources.

A number of existing studies are relevant to this paper. Munro and Sumaila (2002) and Clark, Munro, and Sumaila (2005) investigate the possible negative effects of subsidies for vessel decommissioning schemes. Both papers demonstrate that buyback subsidies generally have a negative impact on resource conservation, if they are anticipated by fishers. Lindebo (2005) examines the impact of the EU's fleet capacity policy. He argues that the misguided use of subsidies for fleet renewal and modernization in the past sent the wrong signal to fishers, but capacity-reducing subsidies had also achieved little success with regard to the long-term, sustainable use of fisheries resources.

The rest of the paper is organized in the following way. In section 2, I set up the basic framework of the analysis. In section 3, I examine the situation of fisheries sector in the long run. In section 4, I analyze the effects of reducing fisheries subsidies in a small open economy in which the world relative price is exogenously given. In section 5 , I extend the analysis to trade between two countries. In section 6 , I state some concluding remarks.

\section{The Basic Model}

In this section, I construct a simple model of worker behavior with a variable supply of labor. ${ }^{6}$ There are two goods: fish, $F$, and manufactures, $M$. Take good $M$ as a numeraire and let the price of good $M$ be one. Denote the price of fish as $p$.

There are $N$ persons, indexed by $i=1, \ldots, N$. Each is endowed with $\bar{x}$ units of labor and supplies $x_{i}$ units of labor. Those persons endogenously supply labor to either the fisheries sector or the manufacturing sector. Note that $L_{i} \equiv \bar{x}-x_{i}$ denotes the leisure of person $i$. Let us consider the fisheries sector first. Suppose that the current fisheries resource stock is $S$. The natural growth rate of the fisheries stock is given by $G(S)$. As is usual in the literature of fishery economics, I use a logistic function: $G(S)=r S(1-S / K)$, where $r>0$ is the intrinsic growth rate and $K$ is the carrying capacity. By devoting $x_{i}$ units of labor to fishing, a person can obtain $F_{i}=E_{i}\left(x_{i} ; F_{-i}, S\right)$ units of fish, where $F_{-i}=\sum_{j \neq i} F_{j}$. I assume that $E_{i}\left(0 ; F_{-i}, S\right)=0, E_{i}^{\prime} \equiv \partial E_{i}\left(x_{i} ; F_{-i}, S\right) / \partial x_{i}>0$, and $E_{i}^{\prime \prime} \equiv \partial^{2} E_{i}\left(x_{i} ; F_{-i}, S\right) / \partial x_{i}^{2}<0$.

\footnotetext{
${ }^{6}$ The basic structure of my model is similar to Chichilnisky's (1994) model of resource extraction by workers from the subsistence sector.
} 
I also assume that $\partial E_{i}\left(x_{i} ; F_{-i}, S\right) / \partial F_{-i}<0$ and $\partial E_{i}\left(x_{i} ; F_{-i}, S\right) / \partial S>0$. In order to obtain explicit solutions, I use a particular functional form for $E_{i}\left(x_{i} ; F_{-i}, S\right)$ :

$$
F_{i}=\left(\gamma S-F_{-i}\right)\left(1-e^{-x_{i}}\right),
$$

where $\gamma>0$ is a constant parameter. Denote that the total catch of fish as $F=\sum_{i=1}^{n} F_{i}$, where $n \leq N$ is the number of persons who engage in fishing. Then, the net change in the resource stock is the natural growth rate minus the total harvest:

$$
\dot{S}=G(S)-F
$$

Person $i$ in the fisheries sector chooses $x_{i}$, taking other fishers' total catch of fish $F_{-i}$ as a given. Thus, I calculate the Nash equilibrium level of fish output, $F_{i}^{N}$. By imposing symmetry, (1) is rewritten as

$$
F_{i}^{N}=\left(\gamma S-(n-1) F_{i}^{N}\right)\left(1-e^{-x_{i}}\right)
$$

which can be solved for $F_{i}^{N}$ :

$$
F_{i}^{N}=\frac{\gamma\left(1-e^{-x_{i}}\right)}{n-(n-1) e^{-x_{i}}} S
$$

The total output of fish in the Nash equilibrium is hence given by

$$
F^{N}=n F_{i}^{N}=\frac{n \gamma\left(1-e^{-x_{i}}\right)}{n-(n-1) e^{-x_{i}}} S .
$$

Then, in the short run (i.e., when $S$ is fixed), I have

$$
\frac{\partial F^{N}}{\partial x_{i}}=\frac{\left.n \gamma e^{-x_{i}}\right)}{\left(n-(n-1) e^{-x_{i}}\right)^{2}} S>0 .
$$

Thus, an increase in $x_{i}$ raises the total output of fish.

In the manufacturing sector, on the other hand, "human capital" is used as a production factor. Person $i$ 's supply of human capital is $h_{i} x_{i}$, where $h_{i}$ is a parameter specific to the person and is a draw from distribution $\Omega(h)$ with support on $[0, \bar{h}]$. One unit of good $M$ is produced by $a$ units of human capital. This implies that the wage $w$ per unit of human capital in the manufacturing sector is given by $w=1 / a$ (Recall that good $M$ is the numeraire). Thus, income for those employed in the manufacturing sector is given by $h_{i} x_{i} / a$. The production of good $M$ is given by $M=\sum_{i=1}^{m} h_{i} x_{i} / a$, where $m \leq N$ is the number of persons employed in the manufacturing sector.

To simplify the analysis, I assume that each person can only work in one sector. Consumer tastes for consumption goods are quasi-concave and weakly separable across the set of consumption goods and leisure. ${ }^{7}$ Utility of consumer $i$ is given by

$$
u^{i}=u\left(\phi(f, m), \bar{x}-x_{i}\right)
$$

\footnotetext{
${ }^{7}$ The assumption of weak separability between consumption goods and leisure is popular in the literature of public economics. See, e.g., Bovenberg and de Mooij (1994).
} 
where $\phi(f, m)$ is a linearly homogenous sub-utility function, and $u$ is strictly increasing and strictly quasi-concave in $\phi$ and $L_{i}$.

I assume that people are myopic in the sense that they maximize their current-period utility in each period. This means that when a person engages in fishing, he decides the optimal level of $x_{i}$ by taking the fish stock $S$ as a given and ignoring the effect of $x_{i}$ on the change in $S$. The reason why I take this approach is that overexploitation of renewable natural resources is mainly caused by short-sighted behavior of people. ${ }^{8}$ Thus, it is important to see the effects on the incentives for short-sighted people.

Person $i$ chooses $m, f$, and $x_{i}$ to maximize $u^{i}$ subject to the budget constraint: $p f+m \leq I^{i}$, where $I^{i}$ is income. When person $i$ earns income in the fisheries sector, the income is given by $I^{i}=q F_{i}+t-\tau$, where $q=p+s$ is the domestic producer price of fish with $s$ being subsidies to support the domestic price, $t$ is income support from the government, and $\tau$ is the lump-sum tax. When the person earns income in the manufacturing sector, on the other hand, income is given by $I^{i}=w h_{i} x_{i}-\tau$. The government's budget is balanced by spending the difference between tax revenue and subsidy payments as government expenditure $g$. Thus, $\tau$ is constant and unaffected by any changes in subsidy payments.

Since $\phi(\cdot)$ is linearly homogenous, it yields

$$
u^{i}=u\left(I^{i} / \beta(p), \bar{x}-x_{i}\right),
$$

where $\beta(p)$ is the true price index associated with $\phi(\cdot)$.

When person $i$ engages in fishing, the optimal supply of labor is determined by maximizing Eq. (6) subject to $I^{i}=q F_{i}+t-\tau$. The first-order condition (FOC) is given by

$$
u_{\phi} \frac{q}{\beta(p)} E_{i}^{\prime}-u_{L}=0
$$

where $u_{\phi} \equiv \partial u_{i} / \partial \phi$ and $u_{L} \equiv \partial u_{i} / \partial\left(\bar{x}-x_{i}\right)$. The second-order condition (SOC) is given by

$$
\frac{\partial^{2} u^{i}}{\partial x_{i}^{2}}=\frac{q}{\beta(p)} E_{i}^{\prime}\left(u_{\phi \phi} \frac{q}{\beta(p)} E_{i}^{\prime}-2 u_{L \phi}\right)+u_{\phi} \frac{q}{\beta(p)} E_{i}^{\prime \prime}+u_{L L} \equiv \Delta
$$

where $u_{\phi \phi} \equiv \partial^{2} u_{i} / \partial \phi^{2}, u_{L \phi} \equiv \partial^{2} u_{i} / \partial\left(\bar{x}-x_{i}\right) \partial \phi$, and $u_{L L} \equiv \partial^{2} u_{i} / \partial\left(\bar{x}-x_{i}\right)^{2}$. I assume that $\Delta<0$ so that the SOC is satisfied.

When person $i$ is employed in the manufacturing sector, on the other hand, the optimal supply of labor is determined by maximizing Eq. (6) subject to $I^{i}=w h_{i} x_{i}-\tau$. The FOC is given by

$$
u_{\phi} \frac{h_{i}}{a}-u_{L}=0
$$

Denote $x_{i}$ that satisfies Eq. (9) by $\tilde{x}_{i}$. The SOC is given by

$$
\frac{\partial^{2} u^{i}}{\partial x_{i}^{2}}=\frac{h_{i}}{a}\left(u_{\phi \phi} \frac{h_{i}}{a}-2 u_{L \phi}\right)+u_{L L}
$$

\footnotetext{
${ }^{8}$ Studies on open-access renewable resources demonstrate this mechanism. See, for example, Gordon (1954) and Brander and Taylor (1997).
} 
I assume the right-hand side is negative so that the SOC is satisfied.

The FOCs (7) and (9) yield the demand functions for leisure $L_{i}^{f *}\left(p, q, I^{i}\right)$ and $L_{i}^{m *}\left(p, w, I^{i}\right)$ when a person works in sectors $F$ and $M$, respectively. As is usually the case, I assume that leisure is a normal good in both cases, i.e., $\partial L_{i}^{f *}\left(p, q, I^{i}\right) / \partial I^{i}>0$ and $\partial L_{i}^{m *}\left(p, w, I^{i}\right) / \partial I^{i}>0$.

\section{Fisheries Stock and Output in the Long Run}

Based on the set-up in the previous section, I analyze the situation of the fisheries sector in the long run. I focus on the analysis in steady states. Denote the Nash equilibrium level of total fish output in steady states by $F_{s s}^{N}$ and the steady-state level of fisheries stock by $S_{s s}$. Then, from (2) a steady state is given by $\dot{S}=0$, or

$$
F_{s s}^{N}=r S_{s s}\left(1-S_{s s} / K\right)
$$

Substitute (4) into (10) to yield the steady-state level of fisheries stock:

$$
S_{s s}=K\left(1-\frac{n \gamma\left(1-e^{-\hat{x}_{i}}\right)}{r\left(n-(n-1) e^{-\hat{x}_{i}}\right)}\right),
$$

where $\hat{x}_{i}$ satisfies (7). Then, I have

$$
\frac{\partial S_{s s}}{\partial \hat{x}_{i}}=-\frac{K n \gamma e^{-\hat{x}_{i}}}{r\left(n-(n-1) e^{-\hat{x}_{i}}\right)^{2}}<0 .
$$

Thus, an increase in $\hat{x}_{i}$ unambiguously reduces the fisheries stock in steady states.

As is well known, the effect of a change in the steady-state level of fish stock on the fish output in steady states depends on the size of the stock. Differentiate (10) with respect to $S_{s s}$ to yield

$$
\frac{\partial F_{s s}^{N}}{\partial S_{s s}}=r\left(1-2 S_{s s} / K\right)
$$

Thus, $\partial F_{s s}^{N} / \partial S_{s s}>0$ if $S_{s s}<K / 2$ and $\partial F_{s s}^{N} / \partial S_{s s}<0$ if $S_{s s}>K / 2$. Note that $S=K / 2$ is known as the maximum sustainable yield (MSY) level of resource stock. The effect of an increase in $x_{i}$ on the total fish output in steady states is then given by

$$
\frac{\partial F_{s s}^{N}}{\partial \hat{x}_{i}}=r\left(1-\frac{2}{K} S_{s s}\right)\left(\frac{\partial S_{s s}}{\partial \hat{x}_{i}}\right) \text {. }
$$

Since $\partial S_{s s} / \partial \hat{x}_{i}<0$, it yields that $\partial F_{s s}^{N} / \partial \hat{x}_{i}<0$ if $S_{s s}<K / 2$ and $\partial F_{s s}^{N} / \partial \hat{x}_{i}>0$ if $S_{s s}>K / 2$. Thus, unlike in the short run (i.e., (5)), an increase in $x_{i}$ reduces the total output of fish in steady states if $S_{s s}<K / 2$, or if the fisheries stock is over-exploited. The following proposition summarizes the results.

Proposition 1 An increase in $\hat{x}_{i}$ always reduces the fisheries stock in steady states. On the other hand, an increase in $\hat{x}_{i}$ reduces (resp. raises) the total output of fish in steady states if the fisheries stock is over-exploited, or $S_{s s}<K / 2$ (resp. not over-exploited, or $S_{s s}>K / 2$ ).

When is the fisheries stock over-exploited? From (11), it is easy to show that $S_{s s}<K / 2$ holds if

$$
\gamma>r / 2 \quad \text { and } \quad \hat{x}_{i}>\log (2 n \gamma-(n-1) r)-\log n(2 \gamma-r),
$$

hold, where $\hat{x}_{i}$ satisfies (7). 


\section{Fisheries Subsidies in a Small Open Economy}

Now, I examine how a reduction in existing fisheries subsidies will affect fisheries stock and output both in the short run and in the long run. The main purpose of this section is to illustrate that the effects of reducing fisheries subsidies on fisheries output are dependent on the economy. I consider two types of subsidies. The first is income supports for workers in the fisheries sector. The second is price supports for fish products. In this analysis, I consider two cases. The first case is that catch quotas are not enforced and there are no alternative employment opportunities for workers in the fisheries sector. The second case is that catch quotas are strictly enforced and there are alternative employment opportunities for workers in the fisheries sector.

In this section, I assume that the country is small in the international market.

\subsection{Unenforced catch quotas and no alternative employment opportunities}

I first consider the case where catch quotas are not enforced and there are no alternative employment opportunities for workers in the fisheries sector. There are no alternative employment opportunities for workers in the fisheries sector if the country is completely specialized in producing good $F$.

Let $\bar{F}$ be the catch quota. If the total catch is below $\bar{F}$ without enforcement, there is no problem. Thus, the implicit assumption in this subsection is that the total catch is greater than $\bar{F}$ even in the absence of fisheries subsidies.

A reduction in income support is measured by a reduction in $t$. This is qualitatively the same as an exogenous reduction in non-labor income. I consider a permanent reduction in $t$. This change does not affect consumption allocation between good $F$ and good $M$. However, it does affect the level of consumption of leisure. Since leisure is a normal good, a reduction in income leads to a reduction in leisure for an individual person. This implies that the person is willing to spend more time fishing. This effect can be obtained by totally differentiating the FOC for the optimal supply of labor (Eq. (7)):

$$
-\frac{\mathrm{d} x_{i}}{\mathrm{~d} t}=\frac{1}{\beta(p) \Delta}\left[u_{\phi \phi} \frac{q}{\beta(p)} E_{i}^{\prime}-u_{L \phi}\right]>0 .
$$

Note that $\Delta<0$ by the SOC, $u_{\phi \phi}<0, E_{i}^{\prime}>0$, and $u_{L \phi}<0$. The overall sign of the terms in the square brackets is negative under the assumption that leisure is a normal good. This result implies that a reduction in $t$ decreases $L_{i}$ and increases $x_{i}$. This is true for all workers who engage in fishing, and all workers in the economy work in the fisheries sector.

Then, since from (5) an increase in $x_{i}$ also increase the fish output in the short run, it yields that a reduction in $t$ unambiguously increases the fish output in the short run. In the long run, by contrast, Proposition 1 implies that the effect of a reduction in $t$ on the steady-state fish output depends on the conditions, while the steady-state fish stock is unambiguously reduced by a reduction in $t$ through an increase in $x_{i}$. If conditions (12) are satisfied, a reduction in $t$ decreases the steady-state fish output. 
Otherwise, it increases the fish output in steady states. These results are summarized in the following proposition.

Proposition 2 In a small open economy (SOE) where catch quotas are not enforced and there are no alternative employment opportunities for workers in the fisheries sector, a permanent reduction in income support $t$ leads to greater fish output in the short run. In the long run, it reduces the steadystate fish stock. It also reduces the steady-state fish output if conditions (12) are satisfied. Otherwise, a permanent reduction in $t$ leads to greater steady-state fish output.

This proposition demonstrates the possibility that a reduction in fisheries subsidies in the form of income support worsens the situation of over-exploited fisheries resources. ${ }^{9}$

Figures 1 and 2 illustrate the effects of a reduction in fisheries subsidies on fish stock and output in the short run and in the long run. The case in which conditions (12) are satisfied is depicted in Figure 1. This corresponds to the case of over-exploited fisheries resources. The horizontal axis measures the level of fish stock, $S$. The inverted-U shape curve is the logistic growth equation, $G(S)$. The solid upward-sloping line is the total catch schedule, $F^{N}(S)$. The current stock level is $S_{t}$ and the current fish output is $F_{t}^{N}$. Since the current level of catch is higher than the natural growth rate, the stock shrinks toward the steady-state level, $S_{s s}$ Then, consider a reduction in $t$. Since it increases $\hat{x}_{i}$, it shifts the $F^{N}$ line up, as illustrated by a upward-sloping broken line. While the current output is higher, $S_{s s}$ shifts to the left and the steady-state level of output, $F_{s s}^{N}$, falls. On the other hand, Figure 2 illustrates the case in which fisheries resources are not over-exploited. As in the previous case, a reduction in $t$ shifts up the $F^{N}$ line and leads to greater current output. However, the steady-state output, $F_{s s}^{N}$, is also greater, despite the lower level of steady-state fish stock.

I next consider a permanent reduction in subsidies $s$. Since $\mathrm{d} s=\mathrm{d} q$, a reduction in $s$ is equivalent to a reduction in $q$. The effects of this price change on the optimal supply of labor can be decomposed as follows:

$$
-\frac{\mathrm{d} x_{i}}{\mathrm{~d} s}=u_{\phi} \frac{E_{i}^{\prime}}{\beta(p) \Delta}+\frac{F_{i}}{\beta(p) \Delta}\left[u_{\phi \phi} \frac{q}{\beta(p)} E_{i}^{\prime}-u_{L \phi}\right] .
$$

In the above equation, the first term represents the substitution effect between leisure and aggregate consumption goods. This term is negative because $\Delta<0$ and $u_{\phi}>0$, implying that a reduction in $s$ will decrease the optimal supply of labor. Since a reduction in $s$ decreases the opportunity cost of leisure, it is optimal for a person to increase leisure and hence to decrease the supply of labor.

The second block of terms, including terms in the square brackets in Eq. (14), measures the income effect, which is positive. The reason is the same as that in Eq. (13). Since a reduction in $s$ decreases nominal income and since leisure is a normal good, then a reduction in $s$ decreases leisure and hence

\footnotetext{
${ }^{9}$ This result implies that fisheries subsidies in the form of income support actually work as a subsidy by which fishermen are bribed to catch fish less. This mechanism is quite similar to that of the subsidy program for farmers to take land out of agricultural production. I would like to thank an anonymous referee for pointing out this implication.
} 
increases the supply of labor. Therefore, the overall effect depends on the relative size of these two effects. Actually, if the elasticity of substitution between leisure and aggregate consumption goods is less than one, the substitution effect is relatively small. In such a situation, the substitution effect is dominated by the income effect and hence a reduction in $s$ increases the supply of labor. The effects of a reduction in $s$ on the fisheries stock and output are then similar to those in Proposition 2.

Proposition 3 In an SOE where catch quotas are not enforced and there are no alternative employment opportunities for workers in the fisheries sector, a permanent reduction in subsidies s leads to greater fish output in the short run if the elasticity of substitution between leisure and aggregate consumption goods is less than one. In such a case, a permanent reduction in s reduces the steady-state fish stock. It also reduces the steady-state fish output if conditions (12) are satisfied. Otherwise, it leads to greater steady-state fish output.

Thus, as long as the elasticity of substitution between leisure and aggregate consumption goods is less than one, the effects of a reduction in $s$ are similar to those of a reduction in $t$.

\subsection{Enforced catch quotas and the presence of alternative employment op- portunities}

I now turn to the case in which catch quotas are strictly enforced and there are alternative employment opportunities for workers in the fisheries sector. The country is diversified, and workers can move across sectors under the conditions specified in the previous section.

A catch quota, $\bar{F}$, is binding in each period if $\bar{F} \leq F=\sum_{i=1}^{n} F_{i}$. Under the binding quota, the output per person is simply given by dividing the quota by the number of workers in the fisheries sector.

As was described in the previous section, the sectoral allocation of workers is determined by the relative level of individual income in the two sectors. As long as the catch quota is binding, the number of persons who work in the fisheries sector, $n$, is endogenously determined by

$$
\frac{p \bar{F}}{n}+t \geq \frac{h_{i} \tilde{x}_{i}}{a} \quad \text { for } \quad i=1, \ldots, n,
$$

where $\tilde{x}_{i}$ on the right-hand side satisfies Eq. (9). If the catch quota is not binding, $n$ is determined by

$$
p E_{i}\left(\hat{x}_{i}\right)+t \geq \frac{h_{i} \tilde{x}_{i}}{a} \quad \text { for } \quad i=1, \ldots, n,
$$

where $\hat{x}_{i}$ on the left-hand side satisfies Eq. (7).

Now, consider a permanent reduction in $t$. If the catch quota is binding in each period, as is obvious from Eq. (15), $n$ decreases because those who have relatively higher human capital move to the manufacturing sector. Consequently, a reduction in $t$ increases the quota per person. However, as long as $\bar{F} \leq n E_{i}\left(\hat{x}_{i}\right)$ holds, the total output of the fisheries sector remains the same in the long run as well as in the short run. The steady-state level of the fisheries stock also remains the same. Thus, 
a reduction in $t$ has no impact on the fisheries stock and output at all. The situation is illustrated in Figure 3. In this figure, the horizontal line indicated as $F=\bar{F}$ represents the catch quota. The current fish stock is at $S_{t}$. At this stock level, the unregulated total catch is at $F_{t}^{N}$, which is higher than the catch quota $\bar{F}$. Thus, as long as the quota is strictly enforced, the actual total catch is $F=\bar{F}$. The resource dynamics leads to the steady-state stock level, $S_{s s}$. The actual total catch remains the same throughout the transition to the steady state. Then, although a reduction in $t$ shifts the unregulated fishing schedule down, the unregulated total catch is still above the quota level. As a result, it has no impact on the fish output and hence the steady-state stock level also remains the same.

However, a further reduction in $t$ may cause $\bar{F}>n E_{i}\left(\hat{x}_{i}\right)$ to hold. If that is the case, then the total output becomes lower both in the short run and in the long run. Since the pressure on the fisheries resource becomes weaker, the steady-state level of the fisheries stock increases. The following proposition summarizes the above analysis.

Proposition 4 In an SOE where catch quotas are strictly enforced and there are alternative employment opportunities for workers in the fisheries sector, a small permanent reduction in income support $t$ has no impact on the fisheries output both in the short run and in the long run and on the steady-state level of fish stock if the catch quota is initially binding. A further reduction in $t$ may decrease the total fish output both in the short run and in the long run and may increase the steady-state level of fish stock.

Consider next a permanent reduction in subsidies $s$. If the catch quota is binding, the number of persons working in the fisheries sector, $n$, is endogenously determined by

$$
\frac{q \bar{F}}{n} \geq \frac{h_{i} \tilde{x}_{i}}{a} \quad \text { for } \quad i=1, \ldots, n .
$$

If the catch quota is not binding, on the other hand, $n$ is determined by

$$
q E_{i}\left(\hat{x}_{i}\right) \geq \frac{h_{i} \tilde{x}_{i}}{a} \quad \text { for } \quad i=1, \ldots, n,
$$

Note that since $s$ affects $\hat{x}_{i}$, in (18) $E_{i}\left(\hat{x}_{i}\right)$ also changes in response to a change in $s$. Otherwise, the effects of a reduction in $s$ are qualitatively similar to those of a reduction in $t$.

Proposition 5 In an SOE where catch quotas are strictly enforced and there are alternative employment opportunities for workers in the fisheries sector, a small permanent reduction in subsidies s has no impact on the fish output both in the short run and in the long run and on the steady-state level of fish stock if the catch quota is initially binding. A further reduction in s may decrease the total fisheries output both in the short run and in the long run and may increase the steady-state level of fish stock.

Unlike the case in the previous subsection, as long as the catch quota is properly set and strictly enforced, fish stocks are maintained in the long run. However, it is sometimes stated that catch quotas are set at levels that result in overfishing. This means that in the case illustrated in Figure 3 the locus of the $F=\bar{F}$ line is above $F_{t}^{N}$. If that is the case, the fisheries stocks can be reduced even if catch 
quotas are strictly enforced. Thus, it is important to note that the results in Propositions 4 and 5 do not guarantee that the fisheries resource stocks in this country are maintained at the appropriate level.

\section{Subsidy Reform in Two-Country Trade}

In this section, I extend the analysis to the case of trade between two countries. There are two countries: Home and Foreign. The basic structure of the economy in the previous sections is retained for both countries. Variables in Home are indicated with no asterisk and those in Foreign are indicated with an asterisk $(*)$. In order to simplify the analysis, I assume that fisheries resource stock exists in each country and that there is no interaction between the resource stocks in the two countries. Consider the case in which Home has a comparative advantage in producing good $M$ and Foreign has a comparative advantage in producing good $F$. More specifically, I impose the following assumption.

Assumption 1 Under free trade without subsidies, Home is diversified and Foreign is completely specialized in producing fish in steady-state equilibrium.

Under this assumption, Home exports good $M$ and imports good $F$ and Foreign exports good $F$ and imports good $M$. Moreover, world demand (i.e., total demand in the two countries) for good $F$ is sufficiently strong to require that even Home, which has a comparative disadvantage in producing good $F$, produces good $F$ in the trading equilibrium.

I also assume that in Foreign the fisheries stock is over-exploited:

Assumption 2 In Foreign, conditions (12) are satisfied so that $S_{s s}^{*}<K / 2$ holds.

Moreover, with respect to the enforcement of catch quotas in the fisheries sector, I assume

Assumption 3 Catch quotas are strictly enforced in Home but are not enforced at all in Foreign.

Consider a situation in which subsidies for income support $t$ is initially provided in each country (and $s=s^{*}=0$ ). Since the subsidies encourage workers to enter the fisheries sector, Foreign continues to specialize in producing fish. In order for Home to produce both goods $t$ must satisfy $p \bar{F} / n+t<h_{j} \tilde{x}_{j} / a$ for some $j$ and $n<N$.

Now consider subsidy reform where $t$ is permanently reduced (but is still positive after the reform) in both countries. From Proposition 2, I know that under Assumption 2 in Foreign a reduction in $t^{*}$ increases fisheries output in the short run and decreases it in the long run, holding $p$ constant. From Proposition 4, for a given $p$ a reduction in $t$ keeps fisheries output constant or may decrease it in Home. In the framework of two-country trade, however, a change in $t$ and $t^{*}$ can also affect the world relative price $p$. I impose the following assumption.

Assumption 4 In Home, the catch quota in the fisheries sector is binding even after a reduction in $t$. 
Under this assumption, a reduction in $t$ does not affect the world supply of fish. On the other hand, a reduction in $t^{*}$ unambiguously increases the world supply of fish in the short run for a given $p$. Thus, it causes $p$ to fall. From Proposition 3, this price change further increases fish output in Foreign if the elasticity of substitution between leisure and aggregate consumption goods is less than one. In the long run, by contrast, a reduction in $t^{*}$ reduces the world supply of fish for a given $p$. Thus, it increases $p$ in steady states. The overall effect in Foreign can be obtained by totally differentiating Eq. (7):

$$
\begin{aligned}
-\frac{\mathrm{d} x_{i}^{*}}{\mathrm{~d} t^{*}}= & \frac{1}{\beta(p) \Delta}\left[u_{\phi \phi} \frac{p}{\beta(p)} E_{i}^{\prime}-u_{L \phi}\right]+\frac{1}{\beta(p) \Delta}\left[\left\{u_{\phi \phi} \frac{p}{\beta(p)} E_{i}^{\prime}-u_{L \phi}\right\}\right. \\
& \left.\times\left\{E_{i}-\frac{I^{i *} \beta^{\prime}(p)}{\beta(p)}\right\}+u_{\phi} E_{i}^{\prime}\left\{1-\frac{p \beta^{\prime}(p)}{\beta(p)}\right\}\right] \frac{\mathrm{d} p}{\mathrm{~d} t^{*}} .
\end{aligned}
$$

In the right-hand side, the first block of terms, including those in the first square brackets, represents the direct effect of a change in $t^{*}$ on $x_{i}^{*}$. As was discussed for Eq. (13), the sign is positive. The terms in the second square brackets represent the indirect effects through a change in $p$. In the second square brackets, there are two elements. The first element measures the income effect. The income effect captures both the effect due to a change in the nominal income and the effect due to a change in the price index that affects real income. As long as $t^{*}$ is sufficiently small, the income effect works to increase the supply of labor. The second element measures the substitution effect between leisure and consumption goods. Although an increase in $p$ increases both the opportunity cost of leisure $\left(p E_{i}^{\prime}\right)$ and the price of aggregate consumption goods $(\beta(p))$, the relative price of leisure to consumption goods increases. This result is obtained from the property $\beta^{\prime}(p)<\beta(p) / p$ that comes from the concavity of $\beta(p)$. Consequently, the second element is negative, meaning that the substitution effect works to reduce the supply of labor. As was discussed in Eq. (14), if the elasticity of the substitution between leisure and aggregate consumption goods is less than one, the substitution effect is dominated by the income effect and hence a reduction in $p$ increases the supply of labor. Since $-\mathrm{d} p / \mathrm{d} t^{*}<0$ in the short run, the overall effect of the indirect effect is positive and hence the indirect effect reinforces the direct effect. In the long run, by contrast, $-\mathrm{d} p / \mathrm{d} t^{*}>0$ holds and hence the indirect effect is negative. Consequently, the overall effect is ambiguous. However, as long as the price change is relatively small and the direct effect dominates the indirect effect, $-\mathrm{d} x_{i}^{*} / \mathrm{d} t^{*}>0$ still holds.

In Home, on the other hand, since a drop in $t$ has no effect on $x_{i}$ as long as the catch quota is binding, it has no impact on the fisheries output and stock. Thus, the following result is obtained.

Proposition 6 When Home and Foreign are characterized by Assumptions 1, 2, 3, and 4 and trade with each other, subsidy reform where $t$ and $t^{*}$ are permanently reduced causes the world catch of fish to increase in the short run if $t^{*}$ is initially sufficiently small and if the elasticity of substitution between leisure and aggregate consumption goods is less than one in Foreign. Although the impact of the subsidy reform in the long run is ambiguous, the steady-state world fish stock decreases unless the price change due to the subsidy reform is large. 
Contrary to conventional wisdom, Proposition 6 shows that worldwide subsidy reform to reduce a type of fisheries subsidies could increase the world catch of fish in the short run. Moreover, since overfishing may be intensified by the subsidy reform, the steady-state level of the world fisheries stock may decrease. This counterintuitive result mainly arises from the endogenous supply of labor. The condition that the elasticity of substitution between leisure and the aggregate consumption goods is less than one is actually plausible and rather general, as Chichilnisky (1994) discusses. Thus, the result of Proposition 6 is not a special case but a plausible case.

Subsidy reform to reduce subsidies $s$ has a similar effect. Suppose that initially $s>0, s^{*}>0$ and $t=t^{*}=0$ in both countries. Then, consider a permanent reduction in $s$ and $s^{*}$. Similarly to Assumption 4, a change in $s$ has no effect on the world supply of fish under the following assumption:

Assumption 5 In Home, the catch quota in the fisheries sector is binding even after a reduction in s.

I then focus on the analysis in Foreign. Recall that in the case of Eq. (14), a change in $s^{*}$ only changes the domestic producer price $q^{*}$. When the world relative price of fisheries product $p$ is endogenously determined, the domestic consumer price and the domestic producer price change due to a change in fisheries subsidies. Totally differentiate Eq. (7) and arrange terms to yield

$$
-\frac{\mathrm{d} x_{i}^{*}}{\mathrm{~d} s^{*}}=\frac{1}{\beta(p) \Delta}\left[u_{\phi} E_{i}^{\prime}+E_{i}\left\{u_{\phi \phi} \frac{q^{*} E_{i}^{\prime}}{\beta(p)}-u_{L \phi}\right\}\right]\left[1+\left(1-\frac{q^{*} \beta^{\prime}(p)}{\beta(p)}\right) \frac{\mathrm{d} p}{\mathrm{~d} s^{*}}\right]
$$

Recall that $\Delta<0$ and from Eq. (14) the overall sign of the terms in the first square brackets is negative if the elasticity of substitution between leisure and aggregate consumption goods is less than one. Moreover, since $\mathrm{d} p / \mathrm{d} s^{*}>0$ in the short run and $\beta^{\prime}(p)<\beta(p) / p$, the overall sign of the second square brackets is positive as long as $s^{*}$ is initially sufficiently small. Thus, it yields that $-\mathrm{d} x_{i}^{*} / \mathrm{d} s^{*}>0$ in the short run. Similar to the case of a reduction in $t$, the effect through a change in $p$ reinforces the direct effect of a change in $s^{*}$ in the short run. In steady states, on the other hand, $\mathrm{d} p / \mathrm{d} s^{*}<0$ may hold. However, as long as the price change is relatively small, $-\mathrm{d} x_{i}^{*} / \mathrm{d} s^{*}>0$ still holds. The following proposition summarizes the results.

Proposition 7 When Home and Foreign, characterized by Assumptions 1, 2, 3, and 5, trade with each other, subsidy reform that $s$ and $s^{*}$ are permanently reduced causes the world catch of fish to increase in the short run if $s^{*}$ is initially sufficiently small and if the elasticity of substitution between leisure and aggregate consumption goods is less than one in Foreign. Although the impact of the subsidy reform in the long run is ambiguous, the steady-state world fish stock decreases unless the price change due to the subsidy reform is large.

Proposition 7 shows that the effects of the subsidy reform that reduces $s$ and $s^{*}$ on the fisheries sector are qualitatively similar to those of the reform that reduces $t$ and $t^{*}$. Under certain conditions, subsidy reform may have unintended impacts on the fisheries sector in the short run and in the long run. 


\section{Concluding Remarks}

In this paper, I investigated the effects of reducing existing subsidies in the fisheries sector. The conventional wisdom is that fisheries subsidies cause overfishing and hence a reduction in fisheries subsidies will contribute to mitigating overfishing and conserving fisheries resources. Conversely, the analysis of this paper suggests that under some conditions the opposite result may be true. That is, a reduction in fisheries subsidies may accelerate overfishing and reduce fisheries resource stocks. The key is how the change in subsidies will affect the incentives of workers who engage in fisheries. If a reduction in subsidies causes workers to put more effort into fishing, it may yield unexpected and undesirable results in counties where fisheries resources are not properly managed. Therefore, in designing new regulations on fisheries subsidies at the WTO, the effects of reducing fisheries subsidies should be carefully examined after consideration of the conditions in different countries. Strengthening fisheries resource management will ensure that subsidy reform mitigates overfishing and conserves fisheries resources.

The focus of this paper was on the effects of subsidies on fisheries output and fish stocks. As mentioned in the introduction, however, the issue that subsidies contribute to the problems of overcapacity and rent dissipation in the fisheries sector is also important. A number of previous studies argue that when harvest is restricted by a total allowable catch (TAC) quota and factor inputs are controlled, fishermen have an incentive to hold overcapacity, which results in rent dissipation (Munro and Scott 1985; Cunningham and Gréboval 2001; Asche et al. 2009). ${ }^{10}$ In this situation, since subsidies increase the incentive to hold overcapacity, a reduction in those subsidies will improve economic efficiency in fisheries sector. ${ }^{11}$ Although this issue is beyond the scope of this paper, the next step of the research is to examine the impact of reducing subsidies on fishing capacity and rent in the fisheries sector.

\footnotetext{
${ }^{10}$ Munro and Scott (1985) were the first to refer this issue as the "Class II common property problem." They argue that this problem arises when the regulator prevents excessive exploitation of resources by imposing quotas but does not limit the number of fishermen competing for the restricted harvests. Rent dissipation emerges because there are an excessive number of vessels and fishermen competing for the limited harvests. Ward et al. (2004) discuss the difference between excess capacity and overcapacity and technical details of estimating current and desired levels of fishing capacity. Asche et al. (2009) empirically investigate whether rent dissipates under individual vessel quota (IVQ) regulations.

${ }^{11}$ I would like to thank an anonymous referee for directing my attention to this issue. Stone (1997) discusses difficulties of assessing the effects of subsidies on overcapacity. Lindebo (2005) analyzes the impact of subsidies on capacity development in the case of European Union's fleet capacity management.
} 


\section{References}

Asche, F., T. Bjørndal, and D.V. Gordon. 2009. Resource Rent in Individual Quota Fisheries. Land Economics 85(2): 279-291.

Bovenberg, A.L., and R.A. de Mooij. 1994. Environmental Levies and Distortionary Taxation. American Economic Review 84(4): 1085-1089.

Brander, J.A., and M.S. Taylor. 1997. International Trade and Open-access Renewable Resources: The Small Open Economy Case. Canadian Journal of Economics 30(3): 526-552.

Chichilnisky, G. 1994. North-South Trade and the Global Environment. American Economic Review 84(4): 851-874.

Clark, C.W. 1990. Mathematical Bioeconomics: The Optimal Management of Renewable Resources, Second Edition. New York: John Wiley \& Sons, Inc.

Clark, C.W., G.R. Munro, and U.R. Sumaila. 2005. Subsidies, Buybacks, and Sustainable Fisheries. Journal of Environmental Economics and Management 50: 47-58.

Cunningham, S., and D. Gréboval. 2001. Managing Fishing Capacity: A Review of Policy and Technical Issues. FAO Fisheries Technical Paper No. 409. Rome: Food and Agriculture Organization of the United Nations.

Gordon, H.S. 1954. The Economic Theory of a Common Property Resource: The Fishery. Journal of Political Economy 62: 124-142.

Khan, A.S., U.R. Sumaila, R. Watson, G. Munro, and D. Pauly. 2006. The Nature and Magnitude of Global Non-fuel Fisheries Subsidies. Catching More Bait: A Bottom-up Re-estimation of Global Fisheries Subsidies, U.R. Sumaila and D. Pauly, eds., pp. 5-37. Fisheries Centre Research Report 14(6). Fisheries Centre, the University of British Columbia, Vancouver.

Lindebo, E. 2005. Role of Subsidies in EU Fleet Capacity Management. Marine Resource Economics 20: $445-466$.

Milazzo, M. 1998. Subsidies in World Fisheries: A Reexamination. World Bank Technical Paper No. 406.

Munro, G.R., and A.D. Scott. 1985. The Economics of Fisheries Management. Handbook of Natural Resource and Energy Economics, Vol. II, A.V. Kneese and J.L. Sweeney, eds., pp. 623-676. Amsterdam: North-Holland.

Munro, G.R., and U.R. Sumaila. 2002. The Impact of Subsidies Upon Fisheries Management and Sustainability: The Case of the North Atlantic. Fish and Fisheries 3: 233-250. 
Organisation for Economic Co-operation and Development (OECD). 2006. Financial Support to Fisheries: Implications for Sustainable Development. Paris: OECD Publishing.

Stone, C.D. 1997. Too Many Fishing Boats, Too Few Fish: Can Trade Laws Trim Subsidies and Restore the Balance in Global Fisheries? Ecology Law Quarterly 24: 505-541.

Ward, J.M., J.E. Kirkley, R. Metzner, and S. Pascoe. 2004. Measuring and Assessing Capacity in Fisheries. 1. Basic Concepts and Management Options. FAO Fisheries Technical Paper No. 433/1. Rome: Food and Agriculture Organization of the United Nations.

World Trade Organization (WTO). 2007. Draft Consolidated Chair Texts of the AD and SCM Agreements. TN/RL/W/213.

World Trade Organization (WTO). 2008. New Draft Consolidated Chair Texts of the AD and SCM Agreements. TN/RL/W/236.

World Trade Organization (WTO). 2011. Communication from the Chairman. TN/RL/W/254. 


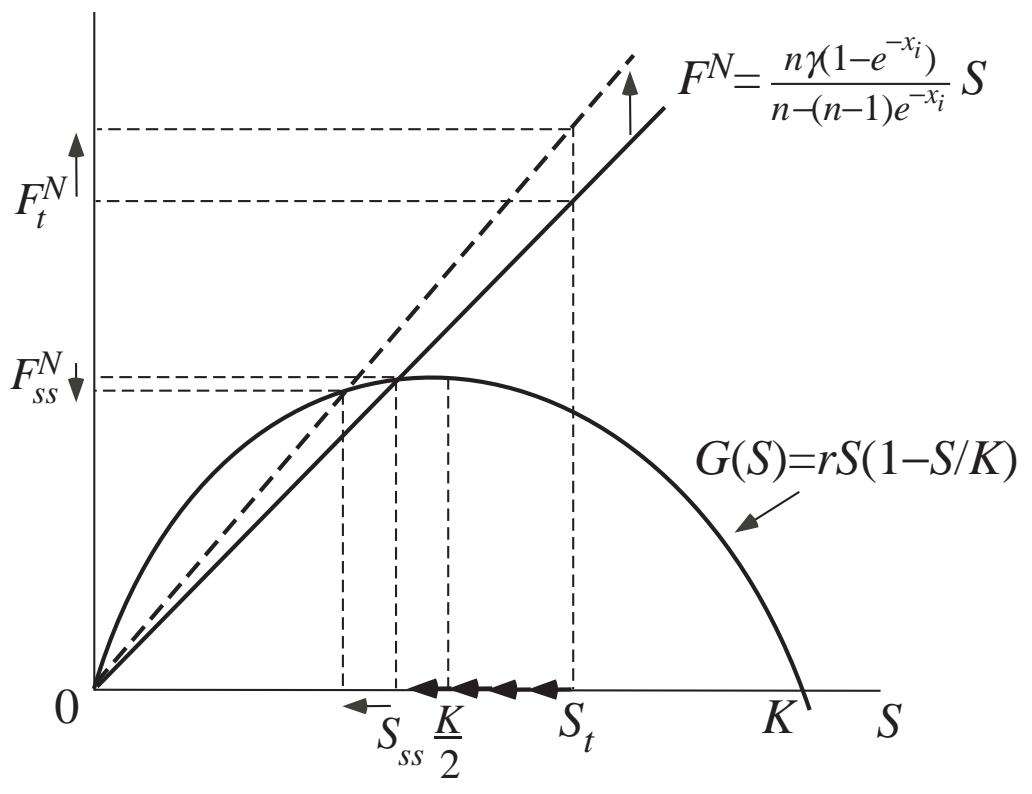

Figure 1: The effect of a reduction in fisheries subsidies when fish is over-exploited 


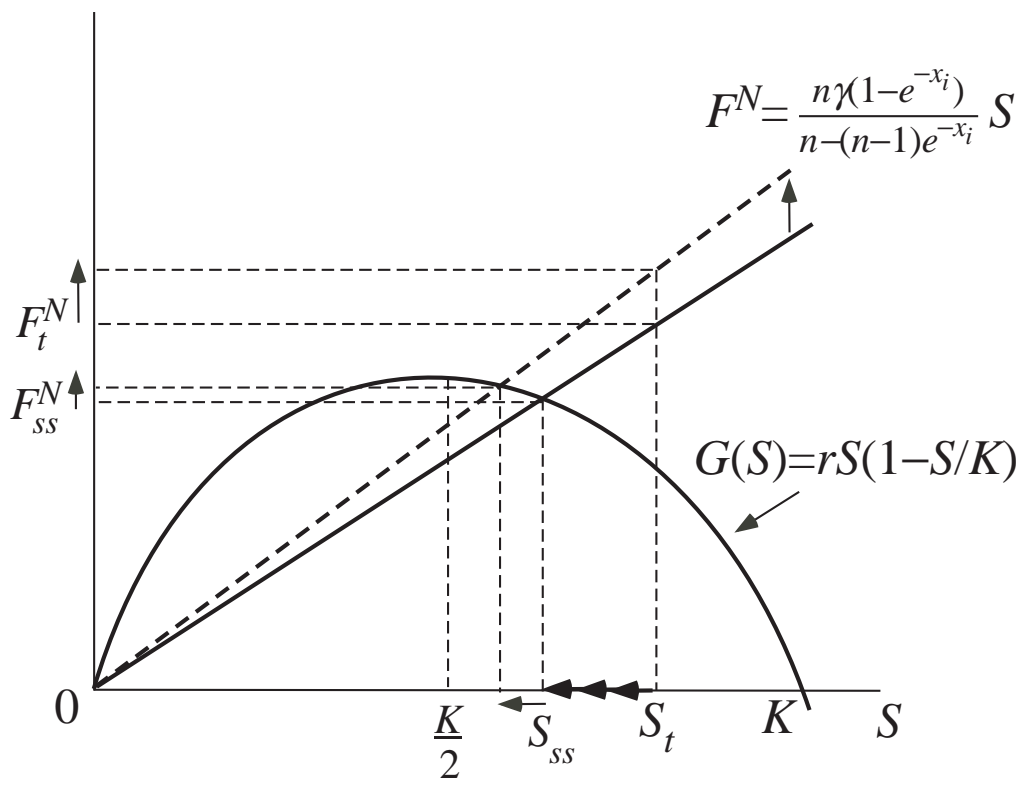

Figure 2: The effect of a reduction in fisheries subsidies when fish is not over-exploited 


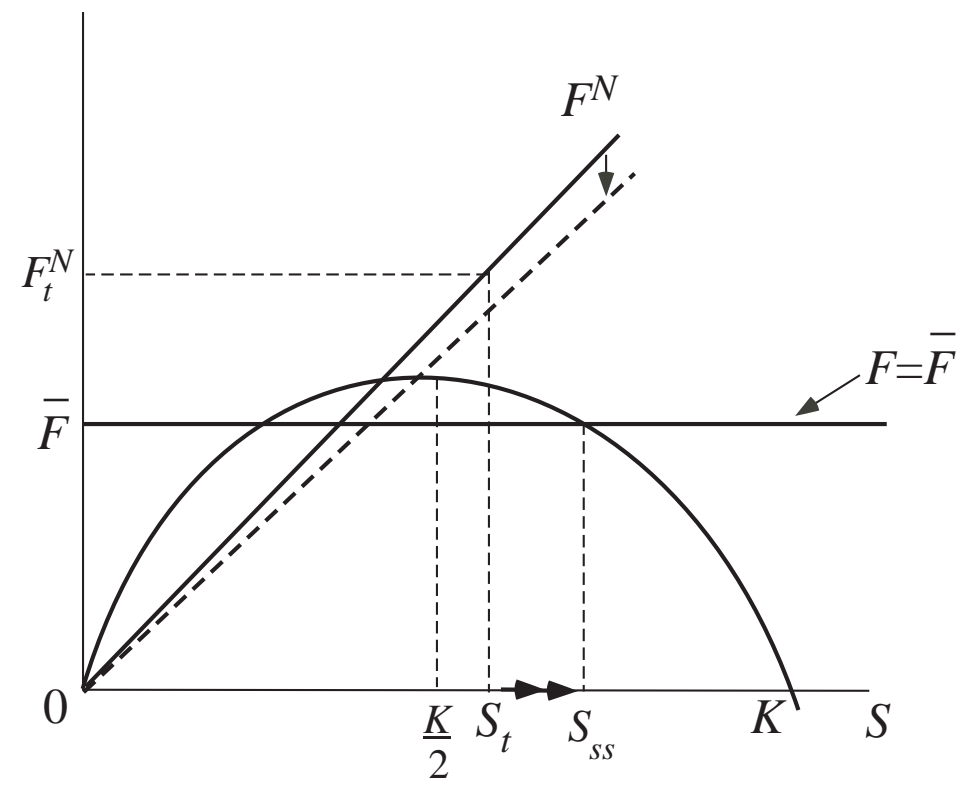

Figure 3: The effect of a reduction in fisheries subsidies when catch quotas are enforced 